\title{
The genus Abundisporus (Hymenomycetes, Basidiomycotina)
}

\author{
ERAST PARMASTO and NILS HALLENBERG
}

PARMASTO, E. \& HALLENBERG, N. 2000: The genus Abundisporus (Hymenomycetes, Basidiomycotina). - Karstenia 40: 129-138. Helsinki. ISSN 0453-3402.

Four species of Abundisporus Ryvarden are described including two new combinations: A. pubertatis (Lloyd) Parmasto and A. subflexibilis (Berk. \& M.A. Curtis) Parmasto. Absorption spectra demonstrated uniformity of the pigments in this genus, but also in Loweporus tephroporus (Mont.) Ryvarden; to distinguish the species, statistical measurement of spore size have been used. Relations of the genera Abundisporus, Perenniporia and Loweporus are discussed.

Key words: Abundisporus, Loweporus, Perenniporia, polypores, taxonomy

Erast Parmasto, Institute of Zoology \& Botany of the Estonian Agricultural University, 181 Riia St., EE 51014 Tartu, Estonia:.E-mail e.parmasto@zbi.ee

Nils Hallenberg, Department of Botany of the University of Göteborg, Carl Skottsbergs gata 22,SE-41319 Göteborg, Sweden.E-mail: Nils.Hallenberg@systbot.gu.se

\section{Introduction}

The genus Abundisporus was described by Ryvarden (1998) for tropical polypores closely related to Perenniporia Murrill and Loweporus Wright but differing in pale yellow non-dextrinoid basidiospores always present in large numbers, and in pale umber to deep purplish brown basidiomata. Four closely related species are known in this genus, differing mainly in slight differences in spore measurements and pore size. The main aim of this study is to evaluate intraand interspecific variation of these characters: are the four taxa really independent species? Beside this, descriptions of the species studied, distribution data and a key to species are given.

\section{Materials and methods}

Specimens from the herbaria FH, K, LE, NY, O, TAA and TRTC were studied as well as five spore prints of $A$. pubertatis obtained in field conditions. In each specimen (or spore sample) 30 randomly taken spores were measured at magnification $\times 1000$. The 90-percent expected tolerance limits of mean spore size were calculated as described by Parmasto and Parmasto (1988). Colour of the basidiomata was described using the handbook by Kornerup and Wanscher (1967). Microscopical study of basidiomata was carried out as described by Gilbertson and Ryvarden (1986: 64-65). Common malt agar has been used as medium in culture studies; culture codes are from Nobles (1965) with emendations by Boidin and Lanquetin (1983). Drop-tests for extracellular oxidases follow Marr's directions (1979), nuclear staining has been made with Giemsa according to Boidin (1958). Absorption spectra (Figs. 1-3) were determined in 330$650 \mathrm{~nm}$ band of aqueous extract of ground to powder dried basidiomata, and of alkalized extract as described by Parmasto and Parmasto (1979: 206) using Zeiss spectrophotometer Specord UV-VIS. Infrared spectra were determined in $2.5-25 \mu \mathrm{m}$ band as $1 \%$ basidiomata powder in $\mathrm{KBr}$ tablet using Zeiss spectrophotometer Specord IR 75. Herbarium abbreviations follow Holmgren et al. (1990).

The results of the morphological and cultural studies are presented under species descriptions; spectrophotometric data are discussed in the concluding part of the paper. 


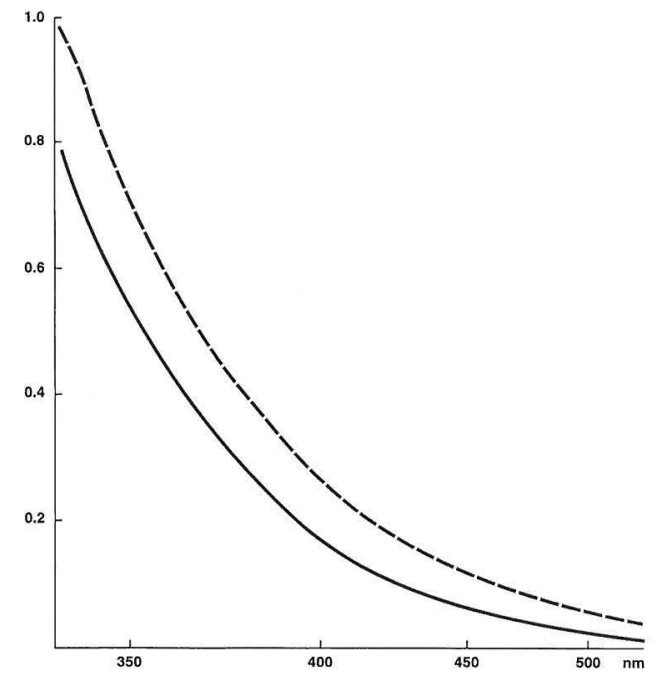

Fig. 1. Absorption spectra of the pigments of Abundisporus fuscopurpureus: of aqueous extract, and of alkalized aqueous extract (broken line).

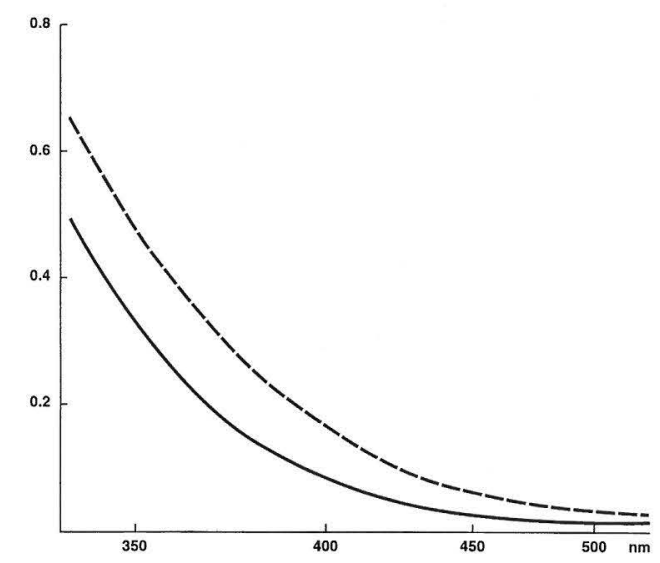

Fig. 2. Absorption spectra of the pigments of Perenniporia (Loweporus) tephropora: of aqueous extract, and of alkalized aqueous extract (broken line).

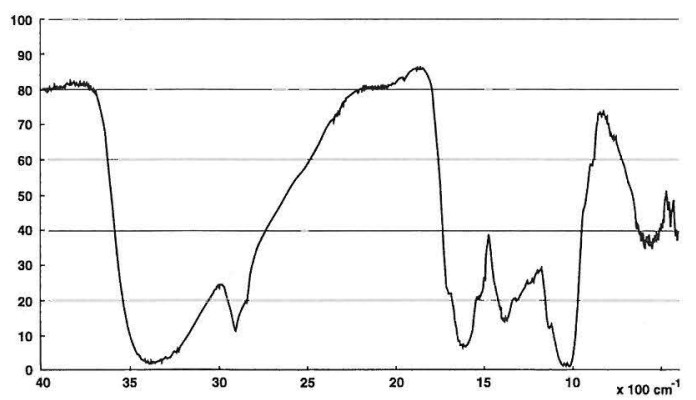

Fig. 3. IR-absorption spectrum of the pigments of Perenniporia (Loweporus) tephropora.
Abundisporus Ryvarden

Belg. J. Bot. 131 (2): 154 (1998).

Basidiomata pileate or resupinate, annual or perennial. Pileus sessile or effused-reflexed, corky, light in weight when dry; pileal surface glabrous, mostly concentrically sulcate and zonate, brown, fuscous to deep purplish brown; context homogeneous, greyish, brown or fuscous, usually with a reddish tint; pore surface pale pinkish in young basidiomata, then pinkish to buff, pale umber, chocolate to vinaceous brown with age; tubes concolorous with pore surface or slightly darker.

Hyphal system dimitic or subtrimitic; generative hyphae with clamps; skeletal hyphae pale yellow to pale brown, slightly dextrinoid; skeleto-binding hyphae few, moderately branched; cystidia absent, cystidioles rarely present; basidia clavate, $8-20 \times 4-9 \mu \mathrm{m}$, with (2) 4 thin sterigmata; spores with slightly or distinctly thickened pale yellowish non-dextrinoid or slightly dextrinoid walls, somewhat truncate or with subangular tip, ellipsoid, 3-6 × 2-5 $\mu \mathrm{m}$; spore print brown.

Tetrapolar (2 species studied), spores uninucleate (1 species studied).

On wood of angiosperms; causes white rot.

Not less than four species in mainly tropical and subtropical zones of Old and New World.

Type: Polyporus fuscopurpureus Pers. (1827) = Abundisporus fuscopurpureus (Pers.) Ryvarden (1998). 


\section{Key to species}

1. Skeletals hyaline. Basidiomata white, cream or ochraceous ...................... Perenniporia Murrill

- Skeletals pale yellow, yellow or brownish. Basidiomata darker coloured ..................................... 2

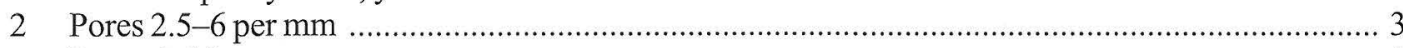

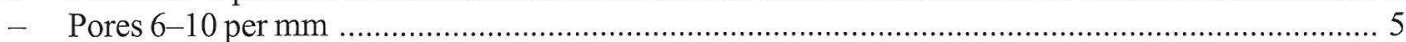

3. Pore surface grey to greyish dirty brown, without violaceous or rosy tint; context dark brown. Spores 4.5-6(-7) × 3.5-4.5 $\mu \mathrm{m}$. ............................. Perenniporia tephropora (Mont.) Ryvarden

(Loweporus tephroporus (Mont.) Ryvarden)

- Pore surface violaceous buff, vinaceous purple fawn or clay buff with a rosy tint; context cinnamon buff to fawn. Spores 2.5-3.5 $\mu$ m wide

4. Pileal surface covered with blackish (in section) crust; pores (4-)5-6 per mm; context indistinctly zonate .

Abundisporus pubertatis

- Surface without crust; pores (2.5-)3.5-4.5 per mm; context zonate A. violaceus

5. Pileal surface without crust. In context mainly skeleto-binding hyphae, skeletal hyphae rare; spores 3.5-5.5 $\mu \mathrm{m}$ wide Perenniporia inflexibilis (Berk.) Corner

- Surface covered with blackish (in section) crust. Skeleto-binding hyphae few, skeletal hyphae

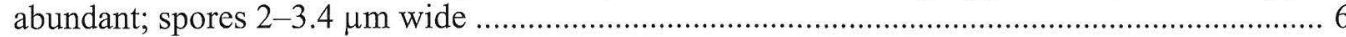

6 Pileal surface zonate. Hyphae strongly swelling in $\mathrm{KOH}$ solution; spores up to $3.9(-4.2) \mu \mathrm{m}$ long A. fuscopurpureus

- Surface azonate or indistinctly zonate. Hyphae not swelling in KOH solution; spores (3.6-)3.8-5 $\mu \mathrm{m}$ long

A. subflexibilis

Abundisporus fuscopurpureus (Pers.) Ryvarden Belg. J. Bot. 131 (2):154 (1998). - Polyporus fuscopurpureus Pers. in Gaudichaud, Voy. Monde, Bot. 172 (1827) non Boud. (1881) = Phellinus torulosus (Pers.) Bourdot \& Galzin. - Loweporus fuscopurpureus (Pers.) Ryvarden in Ryvarden \& Johansen, Prelim. polyp. fl. E. Africa 415, f. 139 a-d, 140 a-d (1980); Corner, Ad Polyporaceas 5:88 (1989). - Polyporus roseoalbus Jungh., Verh. Batav. Genootsch. 17: 43 (1838). - Loweporus roseoalbus (Jungh.) Ryvarden in Ryvarden \& Johansen, Prelim. polyp. fl. E. Africa 415 (1980). - Abundisporus roseoalbus (Jungh.) Ryvarden, Belg. J. Bot. 131 (2): 154 (1998). - Fomes roseotubulatus Lloyd, Mycol. Writ. 5, Letter 67:14 (1918).

Basidiomata perennial, solitary or rarely $2-3$ basidiomata imbricately confluent, semicircular, broadly attached, slightly conchate or almost ungulate, sometimes applanate, exceptionally effuso-reflexed or resupinate, densely corky, usually light in weight when dry. Pileus $2.5-8 \times 4$ $12(-14) \times 0.7-1.5(-2.5) \mathrm{cm}$, densely distinctly concentrically zonate and slightly sulcate, sometimes radially striate, in the middle part uneven or rugulose, first finely tomentose, dark cinnamon or umber, then glabrous, chocolate brown, sienna umber or blackish; margin acute or thin but rounded. Crust present, hard, $0.02-0.1(-0.25) \mathrm{mm}$ thick, black and shiny in section, in very young parts sometimes indistinct; context 2-7(-15) mm thick (about $1 \mathrm{~mm}$ in resupinate specimens), densely cottony or corky, with no zones or indistinctly zoned, light to dark fulvous, sometimes fulvous buff or fulvous umber, darkening to blackish in $\mathrm{KOH}$. Tubes in one strate or indistinctly 2-3(-5)-layered, each stratum up to $10 \mathrm{~mm}$ (totally up to $25 \mathrm{~mm}$ thick), slightly darker than context, light umber, dark fulvous or fulvous umber; pore surface pinkish buff, dark clay buff (sometimes with a violaceous tint), dark vinaceous buff or vinaceous brown when old; sterile margin of the hymenial surface $0.5-2 \mathrm{~mm}$ wide; pores rounded, slightly angular, 7-9(-9.5) per $\mathrm{mm}$, with thin walls and entire margins.

Hyphal system subtrimitic with numerous skeletals and scarce or very rare skeleto-binding hyphae. Generative hyphae sparsely branched, thin-walled, hyaline, with clamps, $1.5-3 \mu \mathrm{m}$ in diameter; skeletal hyphae thick-walled, yellowish to brownish, strongly swelling in $2 \% \mathrm{KOH}, 2.5-$ $6.5 \mu \mathrm{m}$ in diameter $(2-4.5 \mu \mathrm{m}$ in Melzer's Reagent); skeleto-binding hyphae moderately or rarely branched, thick-walled, yellowish, with rare simple septa, 2-4 $\mu \mathrm{m}$ in diam; skeletal and skeleto-binding hyphae slightly or distinctly 
dextrinoid. No cystidia; basidia $15-20 \times 4-5 \mu \mathrm{m}$; spores ellipsoid, with one side flattened, mostly slightly angular, some spores almost truncate, sometimes with $1(-2)$ guttula, with thickened or thick walls, pale yellowish, slightly dextrinoid (pale greyish yellow in Melzer's Reagent), (3.0-) 3.2-3.9(-4.2) × 2.0-2.8(-3.0) $\mu \mathrm{m}$.

Distribution. Angola, Kenya, Malawi, Tanzania, Uganda, Zaïre; Indonesia (Jawa, Krakatau, Sulawesi), Malaysia (Malacca, Sarawak), Papua New Guinea; Australia (Tweed River), New Caledonia; ? South China, ? Japan (Kiushiu), ? Philippines.

Specimens examined. Angola. Loanda, J. Grossweiler (Fomes roseotubulatus, holotype: Lloyd 15529, BPI). Kenya. Coast Prov., Shimba Hills, 12.X. 1972 D. Taylor 863 (O); Shimba Hills, alt. 400 m, 14.II.1973 L. Ryvarden 10472 (O); Western Prov., Kakamega Distr., alt. $1500-1700 \mathrm{~m}, 21 . \mathrm{I} .1970$ L. Ryvarden 5534, 5558 (O); Kakamega Forest, alt. 1500 m, 25-27.I.1973 L. Ryvarden (O); Kakamega Forest, on Croton megaiocarpus, 26.I.1973, no. 2217 (NY); Chogoria track, on Ilex mitis, 1.II.1973, no. 2380 (NY); Central Prov., Mt. Elgon, alt. 2100 m, 23-24.I.1973 L. Ryvarden 9245 (O); Eastern Prov., Mt. Kenya, alt. 1900-2000 m, 31 Jan-1.II.1973 D. Taylor 1060 (O); Mt. Kenya, on Canthium rubrocostatum log, 1.II.1973, no. 2378 (NY). Malawi. Southern Prov., Thyolo Distr., Thyolo Mt., alt. 1100-1400 m, 13.III.1973 L. Ryvarden 11566 (O). Malaisia. Pahang, Tembling, 16.II.1930 J. Corner, det. E. Wakefield as Polyporus calignosus (K); Pahang, Frazers Hill, 28.XI.1930 E. Corner (K). New Caledonia. Kroghio Mts., 24.V.1964 B. Hugheneri, det. D. Reid as P. calignosus (K); Col de la Pirogue, 19.III.1977 Horak (O). Tanzania. E. Usambaras, Kwamkoro Arboretum, Amani, 19.XII.1972, no. 1918 (NY); E. Usambaras, Amani, 20.XII.1972, no. 1990 (NY); Arusha Nat. Park, alt. 1800 m, 8.II.1973 L. Ryvarden 10079 (O); Tanga Prov., Usambara Mts., alt. 800-1000 m, 18-19.II.1973 L. Ryvarden 10642, 10656 (O); Morogoro Prov., Uluguri Mts., alt. $1500-2100$ m, 2426.II.1973 L. Ryvarden 10950 (O). Uganda. W of Masindi, Budongo Forest, alt. 3500 ft, 30.VII.1966 R.F. Cain, H.D. Griffin \& J.C. Krug (TRTC 66.782, 66.795). Zaïre. Kivu Prov., Irangi, III.1972 Rammeloo Z 88 (O).

Remarks. Abundisporus fuscopurpureus is a species easily recognizable by the skeletal hyphae swelling in $\mathrm{KOH}$, the small spores, zonate pileal surface and the context with no zones. Its spore size is normally variable; intraspecific coefficient of variation of spore length is $V=4.6$, of spore width $V=5.6$, of spore length / width $V=2.8$. Loweporus roseoalbus has been distinguished from $A$. fuscopurpureus as a species with different spore size $(2-3 \times 1.5-2 \mu \mathrm{m}$ and $3-4.5 \times 2-3 \mu \mathrm{m}$, respectively); the spore size of the specimens studied by us and identified earlier as two different species do not differ statistically (cf. Table 1).
Table 1. Mean spore measurements (in $\mu \mathrm{m}$ ) and mean spore length / width quotient $Q$ in four Abundisporus species

\begin{tabular}{|c|c|c|}
\hline \multicolumn{3}{|c|}{ A. fuscopurpureus } \\
\hline NY 1990 & $3.25 \times 2.26$ & 1.44 \\
\hline Lloyd 155529 & $3.29 \times 2.15$ & 1.53 \\
\hline Corner 1930 & $3.29 \times 2.22$ & 1.48 \\
\hline Ryvarden 10656 & $3.30 \times 2.39$ & 1.38 \\
\hline Rammeloo Z 88 & $3.31 \times 2.29$ & 1.45 \\
\hline Ryvarden 10950 & $3.31 \times 2.29$ & 1.45 \\
\hline NY 1918 & $3.31 \times 2.32$ & 1.43 \\
\hline Ryvarden 10642 & $3.35 \times 2.33$ & 1.44 \\
\hline TRTC 66.795 & $3.36 \times 2.31$ & 1.45 \\
\hline Corner 1930 & $3.37 \times 2.28$ & 1.48 \\
\hline NY 2217 & $3.39 \times 2.39$ & 1.42 \\
\hline Ryvarden 11566 & $3.39 \times 2.41$ & 1.41 \\
\hline TRTC 66.782 & $3.41 \times 2.29$ & 1.49 \\
\hline Hugheneri 1964 & $3.41 \times 2.34$ & 1.46 \\
\hline Taylor 1060 & $3.42 \times 2.37$ & 1.44 \\
\hline Ryvarden $5534-1$ & $3.43 \times 2.43$ & 1.41 \\
\hline Taylor 863 & $3.44 \times 2.26$ & 1.52 \\
\hline NY 2380 & $3.49 \times 2.46$ & 1.42 \\
\hline Ryvarden 9397 & $3.50 \times 2.47$ & 1.42 \\
\hline Ryv. 10472-1 & $3.59 \times 2.34$ & 1.53 \\
\hline NY 2378 & $3.54 \times 2.43$ & 1.46 \\
\hline Ryvarden $5558-1$ & $3.54 \times 2.50$ & 1.42 \\
\hline Ryv. $10472-2$ & $3.55 \times 2.42$ & 1.47 \\
\hline Ryvarden 5534-2 & $3.61 \times 2.53$ & 1.43 \\
\hline Ryvarden $5558-2$ & $3.64 \times 2.59$ & 1.41 \\
\hline Ryvarden 10079 & $3.66 \times 2.61$ & 1.40 \\
\hline Ryvarden 9245 & $3.78 \times 2.69$ & 1.41 \\
\hline Horak 1977 & $3.91 \times 2.64$ & 1.48 \\
\hline Mean & $3.46 \times 2.39$ & 1.45 \\
\hline Coefficient of & $4.6 \quad 5.6$ & 2.8 \\
\hline
\end{tabular}

variation $V$

$90 \%$-expected tolerance limits:

$3.18-3.73 \times 2.16-2.62 ; 1.38-1.52$

$\begin{array}{lll}\text { A. pubertatis } & & \\ \text { TAA } 105775 & 4.24 \times 2.59 & 1.64 \\ \text { TAA } 105776 & 4.47 \times 2.73 & 1.64 \\ \text { TAA 105773 } & 4.61 \times 3.00 & 1.54 \\ \text { O. querc. type } & 4.64 \times 2.91 & 1.59 \\ \text { TAA 105761 } & 4.66 \times 3.07 & 1.52 \\ \text { TAA } 106802 & 4.68 \times 2.87 & 1.63 \\ \text { TAA 105777 } & 4.68 \times 3.01 & 1.55 \\ \text { TAA 105763 } & 4.69 \times 3.02 & 1.55 \\ \text { TAA 106259 } & 4.72 \times 2.95 & 1.60 \\ \text { O. quercinus } & 4.81 \times 2.86 & 1.68\end{array}$

(another part of the type)

\begin{tabular}{|c|c|}
\hline Mean & $4.62 \times 2.90$ \\
\hline Coefficient of & $3.5 \quad 5.2$ \\
\hline
\end{tabular}

variation $V$

90\%-expected tolerance limits:

$4.31-4.93 \times 2.62-3.18 ; 1.49-1.70$

\section{A. subflexibilis}

Rick 1930

$4.05 \times 2.53$

1.60

NY 2856

$4.07 \times 2.58$ 
Ryvarden 10737

NY 775

Lowy et al. 560

Wurduch 39468

Malawi, BM 291

Ryvarden 10445

Ryvarden 10463

TRTC 66.1489

Wright (type)

Wright 159

\section{Mean}

Coefficient of

variation $V$

90\%-expected tolerance limits:

$3.88-4.67 \times 2.35-2.95 ; 1.50-1.73$

\begin{tabular}{lll} 
A. violaceus & & \\
TRTC 66.1244 & $4.59 \times 3.38$ & 1.36 \\
TRTC 66.124 & $4.92 \times 3.23$ & 1.52 \\
Ryvarden 10775 & $5.19 \times 3.21$ & 1.62 \\
NY 2951 & $5.22 \times 3.36$ & 1.55 \\
Mean & $\mathbf{4 . 9 8} \mathbf{3 . 3 0}$ & $\mathbf{1 . 5 1}$ \\
\hline
\end{tabular}

The eastern-northeastern boundary of the distribution area of this species is unclear. The difference between $A$. fuscopurpureus and A. pubertatis was not clear for the earlier authors; however, it is questionable if the areas of both species really overlap in East Asia.

There is one herbarium specimen studied by us which deviates from the description given above (Zaïre: Irangi, Kivu, IV.1972 J. Rammeloo 291, O). All characteristics including spore size (means: $3.29 \times 2.28 \mu \mathrm{m} ; Q=1.44$ ) are typical for this species except hard, Phellinus-like consistency of the heavy basidiome and presence of thick (up to $0.5 \mathrm{~mm}$ ) crust on its surface.

\footnotetext{
Abundisporus pubertatis (Lloyd) Parmasto comb. nova

- Basionym: Polyporus pubertatis Lloyd, Mycol. Writ. 4: 358, f. 692 (1915). - Fomitopsis pubertatis (Lloyd) Imaz., Bull Tokyo Sci. Mus. 6:92 (1943); Imazeki \& Hongo, Colour. ill. fungi Japan 2, pl. 50, f. 292. - Nigroporus pubertatis (Lloyd) Teng, Fungi China 762 (1963). - Loweporus pubertatis (Lloyd) Hattori, Bull. Nat. Sci. Mus. Tokyo B 21 (2):99 (1995). - Osmoporus quercinus Bondartsev \& L. Vass., Not. Syst. Sect. Crypt. Inst. Bot. Ac. Sci. URSS 16:114, f. 1-3 (1963).

Basidiomata perennial, solitary or 2-3 basidiomata laterally confluent, semicircular, broadly
}

attached, ungulate or triquetrous in radial section; sometimes effused-reflexed or almost resupinate; densely corky. Pileus $0.5-2.5(-3) \times 2-6$ $\times 1-2 \mathrm{~cm}(2-7 \mathrm{~cm}$ in diam and $0.5-1.5 \mathrm{~cm}$ thick when resupinate), azonate or indistinctly zonate, in old specimens with 1-2 deep concentrical furrows, uneven, somewhat tuberculate, vinaceous buff, then fawn, greyish brown and at base almost black when old. Crust usually absent, but present in old specimens, hard, $0.02-0.1 \mathrm{~mm}$ thick, black in section, usually covered with a thin layer of cottony context. Context up to 10 $\mathrm{mm}$ thick (1-3 $\mathrm{mm}$ in resupinate specimens), indistinctly zoned in section, fawn or with a slight vinaceous tint. Tubes in one strate or $2-4(-5)$ layered, each stratum $2-4(-5) \mathrm{mm}$ (totally up to $15 \mathrm{~mm}$ ), trama concolorous with the context but hymenial surface whitish pruinose. Pore surface covered with vinaceous pruina, brownish when bruised, later vinaceous grey or almost vinaceous purple fawn. Pores rounded or slightly angular, 0.1-0.2 $\mathrm{mm}$ in diam, (4-)5-6 per mm, with more or less entire margins. New tube layer usually narrower (less wide) than the older one, and the margin of the pore surface stepped (like that in Heterobasidion annosum (Fr.) Bref.).

Hyphal system subtrimitic with numerous skeletals and few skeleto-binding hyphae. Generative hyphae rare, scarcely branched, thinwalled, hyaline or yellowish, with clamps, 2-3.5 $\mu \mathrm{m}$ in diameter. Skeletal hyphae thick-walled, dark yellow or brownish, not swelling in $2 \%$ $\mathrm{KOH}, 2-4 \mu \mathrm{m}$ in diameter; skeleto-binding hyphae moderately or rarely branched, thickwalled, yellowish, $2-3.5 \mu \mathrm{m}$ in diameter; skeletal and skeleto-binding hyphae slightly dextrinoid. Cystidia none; basidia 8-10 × 4.5-5.5 $\mu \mathrm{m}$. Spores ellipsoid, one side flattened, some slightly angular or subtruncate, usually with 1-2 guttula, more or less thick-walled, yellowish, slightly dextrinoid, 4-5.2 × 2.5-3.5 $\mu \mathrm{m}$; spore print vinaceous brown.

Causes white rot on wood.

Culture characters of the specimen TAA 106242 (culture no. GB 1415). Aerial mycelium absent, except in old parts, where it is pellicularfelty, whitish - light ochraceous-rose-coloured; advancing zone even, submerged; odour slightly fruity. After 3 weeks' growth the whole colony was uniform, with a scattered downy aerial mycelium. All hyphae thin-walled and constantly provided with clamps at the septa. After 6 weeks 
growth no clamps were found in the agar mycelium, covering the greatest part of the plate; hyphae thin-walled, regularly branched, $2-3.5 \mu \mathrm{m}$ wide. Aerial mycelium in the old part consists of more differentiated hyphae: A) hyphae with thin to slightly thickened walls, $1.5-4 \mu \mathrm{m}$ wide, constantly clamped, frequently with irregular swellings in apices and branching nodules (Fig. $4 \mathrm{~A}$ ), hyaline but with light-refracting content (in phase contrast microscope); B) binding hyphae, thick-walled, 1-3 $\mu \mathrm{m}$ wide, without clamps, more or less brown-pigmented (Fig. 4 B). Plates covered in 6 weeks.

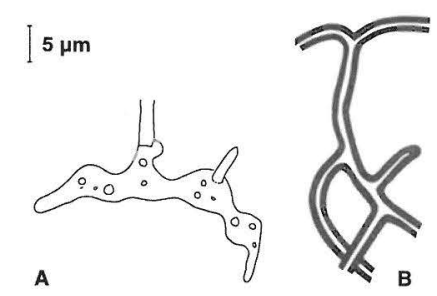

Fig. 4. Abundisporus pubertatis, aerial mycelium of a culture: A - swelling in an apex of a hypha; B - skeletobinding hyphae.

Code. 2a. 4. 8. 26.32.(36.) (37.) 38. 50.54.60.61.

Oxidase reactions. Weak to moderate staining in Syringaldazine, Gum Guaiac and Guaiacol. No staining with 1-Naphtol, p-cresol and L-Tyrosine.

Polarity. Tetrapolar, but the polarity pattern obtained was imperfect:

$\mathrm{A}^{1} \mathrm{~B}^{1}: \mathrm{SS}-1,2 ; \quad \mathrm{A}^{2} \mathrm{~B}^{1}: \mathrm{SS}-3,4,5,6,8,9,15 ;$

$\mathrm{A}^{1} \mathrm{~B}^{2}$ : SS-7, 10; $\quad \mathrm{A}^{2} \mathrm{~B}^{2}$ : SS-11, 17.

Matings between SS-7 and SS-11 were negative in spite of repeated confrontations.

Cytology. Spores uninucleate. SS-mycelium with uninucleate cells, constantly clamped PSmycelium dicaryotic.

Nuclear behavior. According to the cytological study, A. pubertatis has a normal behavior. The diagnostic study of the mycelium indicates that the occurrence of clamps is variable, according to conditions of aeration. This has hitherto only been associated with astatocoenocytic behavior where, however, both SS-mycelium and submerged PS-mycelium have pluri- to multinucleate cells (see Boidin \& Lanquetin 1984).

Distribution. Russia (Primorski Terr.), Japan (Honsju), China (Yunnan and Zhejiand Prov.).
Specimens examined. Russia. Primorski Terr., Vladivostok, Botanical Garden, on Quercus mongolica, 5.X.1960 L. Vassiljeva (LE, lectotype of Osmoporus quercinus); Hasan Distr., Kedrovaya Pad' Nature Reserve, on Quercus mongolica, 23.VI.1984 E. Parmasto (TAA 105761, 105763, 105767), 24.VI.1984 E. Parmasto (TAA 105773, 105775-105778), 18.VII.1985 U. Kõljalg (TAA 106802; O, sine num.), 24.VII.1985 E. \& I. Parmasto and U. Kóljalg (TAA 106242, 106259).

Remarks. Abundispous pubertatis is externally very similar to Fomitopsis rosea (Alb. \& Schwein. : Fr.) P. Karst., but also to Melanoporia castanea (Imazeki) T. Hattori \& Ryvarden, which differ in dimitic hyphal system without skeletobinding hyphae and type of rot (brown rot fungi). The very closely related $A$. subflexibilis has spores quite similar to those of $A$. pubertatis (Fig. 5) but differs by smaller pores (6.5-8 per $\mathrm{mm}$ ), sometimes also by a concentrically zonate and sulcate pileal surface. Both species are geographically vicarious, $A$. subflexibilis occurs in Africa, Central and South America.

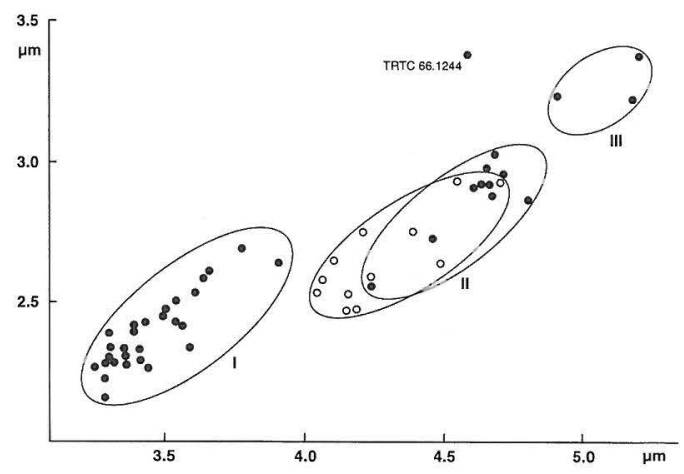

Fig. 5. Mean spore size of Abundisporus species. I-A. fuscopurpureus; II -A. pubertatis $(\bullet)$ and A. subflexibilis (o), III - A. violaceus.

A. pubertatis has been synonymized with $A$. roseoalbus ( $=A$. fuscopurpureus) by Ryvarden (Ryvarden \& Johansen, 1980), but they have different size of pores and spores.

Abundisporus subflexibilis (Berk. \& M.A. Curtis) Parmasto comb. nova

- Basionym: Polyporus subflexibilis Berk. \& M.A. Curtis, J. Linn. Soc. Bot. 10: 311 (1868).- 
Fomes subflexibilis (Berk. \& M.A. Curtis) Sacc., Syll. fung. 6: 178 (1888). - Polystictus vibratilis Berk. \& M.A. Curtis, J. Linn. Soc. Bot. 10:314 (1868).

Basidiomata perennial (sometimes annual?), solitary or rarely 2-3 basidiomata confluent and imbricate, semicircular, broadly attached, slightly conchate or almost ungulate, rarely applanate, sometimes effused-reflexed, densely corky, light in weight when dry. Pileus $2.5-6.5 \times 4-11 \times 0.5-3$ $\mathrm{cm}$; pileal surface with no zones when young but afterwards with one broad marginal zone or indistinctly concentrically zonate and slightly sulcate, at base uneven, fulvous umber, umber or dark date brown, at base later blackish; marginal zone sometimes fulvous clay. Crust in perennial specimens present, hard, $0.03-0.15 \mathrm{~mm}$ thick, black and shiny in section. Margin acute or thin but rounded. Sterile margin of the pore surface $0.5-$ $1.5 \mathrm{~mm}$ wide. Context $5-20 \mathrm{~mm}$ thick $(1-3 \mathrm{~mm}$ in resupinate part of the basidiome), densely cottony or corky, not zonate or indistinctly zoned, fulvous, brownish fulvous or umber. Pore surface glaucous or bay with a vinaceous tint, fulvous when bruised, then fulvous, fulvous umber or date brown; pores rounded, $6.5-8.5$ per $\mathrm{mm}$, with thin, entire walls.

Hyphal system subtrimitic with numerous skeletals and more rare skeleto-binding hyphae. Generative hyphae scarcely branched, thinwalled, hyaline or slightly yellowish, with clamps, $1.5-3 \mu \mathrm{m}$ in diameter. Skeletal hyphae thick-walled, yellowish to brownish yellow, not swelling in 2\% KOH solution, $2-5 \mu \mathrm{m}$ in diameter; skeleto-binding hyphae moderately or rarely branched, thick-walled, yellowish, 1.5-3.5 $\mu \mathrm{m}$ in diameter; skeletal and skeleto-binding hyphae slightly dextrinoid. Cystidia none; basidia 13-17 × 5-5.5 $\mu \mathrm{m}$. Spores ellipsoid, one side flattened, slightly angular, some rare spores almost truncate, usually with 1-2 guttula, with thickened or thick walls, slightly or distinctly yellowish, slightly dextrinoid, (3.6-)3.8-5 × 2.2-3.2(-3.4) $\mu \mathrm{m}$.

Distribution. Brazil, Cuba, Kenya, Malawi, Tanzania, Venezuela.

Specimens examined. Brazil. Sao Leopoldo, Rio Grande do Sul, 1930 J.E. Rick (FH); SE of Rio Branco, 9.X.1980 B. Lowy et al. 560 (NY); between Rio Branco and Quixada, 19.X.1980 B. Lowy et al. 775 (NY). Cuba. C. Wright 165 (K, holotype of Polyporus subflexibilis); C. Wright 159 (K, holotype of Polyporus vibratilis). Kenya. Coast Prov., Shimba Hills, 24.VIII.1966 R.F. Cain et al. (TRTC 66.1489); Shimba Hills, 14.II.1973 L. Ryvarden 10445, 10463 (O). Mala- wi. BM 291 (Herb. Univ. Malawi). Tanzania. Tanga Prov., Usambara Mts., 18-19.II.1973 L. Ryvarden 10737 (O); Amani East Usambaras, on Hura crepitans, 19.II.1973, no. 2856 (NY). Venezuela. Esludo Maragas, Hemuga Area, 25.IX.1955 J. Wurduch 39468 (O).

Remarks. Abundisporus subflexibilis has been synonymized with $A$. roseoalbus ( $A$. fuscopurpureus) by Ryvarden (Ryvarden \& Johansen, 1980), a closely related species distinguished by its shorter, up to $4 \mu \mathrm{m}$ long spores, and hyphae strongly swelling in $\mathrm{KOH}$ solution. Another similar species is $A$. violaceus, separated by bigger spores $(4.5-5.5 \times 2.8-3.5 \mu \mathrm{m})$ and soft, light coloured pileal surface without a crust. The difference between $A$. subflexibilis and $A$. pubertatis is described at the last named species. It is possible that the taxa are two vicarious subspecies.

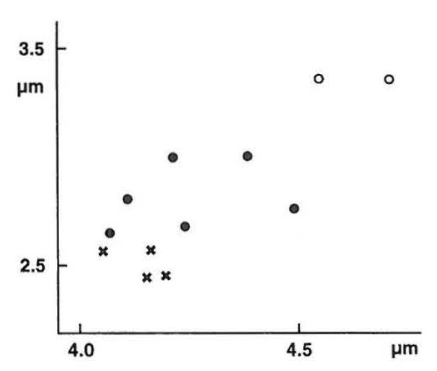

Fig. 6. Mean spore size in Abundisporus subflexibilis: collections from Venezuela and Brazil $(\times)$, Africa $(\bullet)$ and Cuba (o).

According to the spore size, three populations may be distinguished in A. subflexibilis: Cuban population, African and Venezuelan-Brazilian ones (Fig. 6). However, the number of specimens studied is too low to assert that they are different taxa.

Abundisporus violaceus (Wakef.) Ryvarden Belg. J. Bot. 131 (2): 154 (1998). - Polystictus violaceus Wakef., Kew Bull. Misc. Inf. 1916:72 (1916). - Loweporus violaceus (Wakef.) Ryvarden in Ryvarden \& Johansen, Prelim. polyp. fl. E. Africa 417, f. $140 \mathrm{~g}$ (1980).

Basidiomata annual or perennial, solitary or imbricate and laterally fused, dimidiate, slightly conchate or semitriquetrous in section, at base with a slightly decurrent tube layer, corky, light in weight when dry. Pileus $3-5 \times 3-10 \times 0.5-3 \mathrm{~cm}$, 
surface without zones, uneven, somewhat tuberculate or irregularly warted, finely adpressed-velutinate, soft at touch, greyish cinnamon, ochraceous to buff with a pink to violet tinge; crust absent. Margin acute or rounded-acute, entire; sterile margin of the hymenophore surface up to $12 \mathrm{~mm}$ wide. Context $4-15(-20) \mathrm{mm}$ thick, fibrouscottony or soft-corky, zonate, cinnamon buff or light cinnamon, darkening to dark castaneous brown in $\mathrm{KOH}$ solution. Tubes in one strate, (2-) 4-8 mm deep; pore surface dark vinaceous buff, ochraceous pink or clay buff with a rosy tint; pores rounded or slightly angular, (2.5-)3.5-4.5 per $\mathrm{mm}$, with thin or slightly thickened walls and entire margins.

Hyphal system dimitic or subtrimitic with numerous skeletals and rare or none skeletobinding hyphae. Generative hyphae scarcely branched, thin-walled, hyaline, with clamps, 2-4 $\mu \mathrm{m}$ in diameter. Skeletal hyphae thick-walled, yellow or pale brown, $2.5-5 \mu \mathrm{m}$ in diam, almost not swelling in $2 \% \mathrm{KOH}$ solution; skeleto-binding hyphae moderately branched, thick-walled, brownish, 2-4 $\mu \mathrm{m}$ in diam; skeletal and skeletobinding hyphae slightly, rarely - strongly dextrinoid. Cystidia none; basidia $15-20 \times 3.5-5 \mu \mathrm{m}$, with 4 thin, 3-4 $\mu \mathrm{m}$ long sterigmata. Spores ellipsoid, with one side flattened, slightly angular, some few spores almost truncate, usually with 12 guttula, thick-walled, slightly or distinctly yellowish, slightly dextrinoid (greyish yellow in Melzer's Reagent), 4.5-5.5(-6) ×2.8-3.5(-4) $\mu \mathrm{m}$.

Distribution. Kenya, Tanzania, Uganda (Wakefield, 1916; Ryvarden \& Johansen, 1980).

Specimens examined. Kenya. Central Prov., W of Endebess, Mt. Eglon Forest Station, alt. $8000 \mathrm{ft}$, 2.VIII.1966 R.F. Cain et al. (TRTC 66.124). Tanzania. Tanga Prov., Lushoto Distr., Usambara Mts., alt. 16002000 m, 21-22.II.1973 L. Ryvarden 10775 (O); Lushoto, Sungur Forest, W Usambawar, on Podocarpus sp., 21.II.1973, no. 2951 (NY). Uganda. Namutambula Forest, I.1915 Maitland (K, holotype).

Remarks. The type of this species is sterile; only two spores have been seen by us: one unripe one, still attached to a basidium was $4.4 \times$ $2.8 \mu \mathrm{m}$, and another, damaged spore was about $5 \times 3 \mu \mathrm{m}$.

There is one specimen collected in Kenya (W of Endebess, alt 8,000 ft, 2.VIII.1966 R.F. Cain et al., TRTC 66.1244) which differs from typical Abundisporus violascens by being 3-layered in older parts of the basidiome, and tubes up to 4 $\mathrm{mm}$ long in each layer, and short spores (mean size of 30 spores measured: $4.59 \times 3.38 \mu \mathrm{m})$.
Abundisporus violascens is easily recognizable thanks to its large spores and pores, and absence of crust on its soft pileal surface.

\section{Species incertae sedis}

Loweporus inflexibilis (Berk.) Ryvarden

Ryvarden in Ryvarden \& Johansen, Prelim. polyp. fl. E. Africa 413, f. 139 e-g (1980). - Polyporus inflexibilis Berk., Hook. J. Bot. 8:199 (1856). Perenniporia inflexibilis (Berk.) Corner, Beih. Nova Hedwigia 96:107 (1989).

A good description of this species is given by Ryvarden and Johansen (1980). It differs from the species of Abundisporus by absence of rosy, reddish or violaceous colour, and abundance of dextrinoid binding hyphae. We have not studied specimens of this fungus; according to the description given by Ryvarden and Johansen (1980), it has abundant yellowish brown, weakly dextrinoid spores; according to Corner (1989), the spores are white. This species was not mentioned by Ryvarden in his later paper (1998) when discussing on the taxonomy of the species of Loweporus.

Loweporus castaneus Corner, Beih. Nova Hedwigia 96: 86 (1989).

L. corticola Corner, Beih. Nova Hedwigia 96: 88 (1989).

L. mollis Corner, Beih. Nova Hedwigia 96: 91 (1989).

L. ochraceicinctus Corner, Beih. Nova Hedwigia 96: 91 (1989).

L. pileoliferus Corner, Beih. Nova Hedwigia 96: 92(1989).

L. rufescens Corner, Beih. Nova Hedwigia 96: 93 (1989).

All six species of Loweporus mentioned above have white spores and obviously do not belong to the genus Abundisporus.

\section{Discussion}

Only few groups of polypores have basidiomata with pinkish, rose-coloured or violaceous context and pore surface. Seven species of Fomitopsis are somewhat similar to Abundisporus species not only by their colour but also by a dense crust on their perennial pilei which sometimes is present (cf. Carranza-Morse \& Gilbertson 1986). Nevertheless, Fomitopsis species are distinctly 
different by their distinctly trimitic hyphal system, hyaline cylindric or allantoid spores, brown rot and bipolar mating system.

Only the colour of basidiomata, skeletal hyphae and spores are the characteristics which enable to discriminate the closely related genera Abundisporus, Perenniporia Murrill and Loweporus Wright. Corner (1989) tried to distinguish Perenniporia and Loweporus on base of different hyphal systems, but in this group of fungi this character is too variable and hyphal types are not clearly distinguishable. Perenniporia is characterized by mainly white or ochraceous colour of basidiomata and skeletal hyphae; spores are hyaline (spore print is white), variable in size, in many cases strongly dextrinoid. The type of Loweporus, L. tephroporus has grey to greyish dirty brown pore surface, ochraceous to pale brown skeletals which turn pale olivaceous in $\mathrm{KOH}$ solution, and small hyaline to yellow spores, dextrinoid in various degree. Basidiomata of the species of both genera are without any violaceous or rosy tint. In Abundisporus, basidiomata have pinkish to buff, pale umber, chocolate or vinaceous brown colour; spores are nondextrinoid or only slightly dextrinoid, yellow, brownish or (in spore print) vinaceous brown.

The difference in colour is striking between Loweporus tephroporus and Abundisporus species, but this is possibly mainly caused by structure of basidiomata and location of their pigments on hyphae, not by presence of different pigments. Absorption spectra of aqueous and alkalized aqueous extracts of 16 basidiomata (A. fuscopurpureus, A pubertatis, A. subflexibilis, A. violaceus, L. tephroporus) are all quite similar and unspecific in the region of visible light, representing more or less gently declining curves without any maxima, minima or inflexions (Figs. 1-2). Infrared spectra of $A$. fuscopurpureus (TAA 10472), A. pubertatis (TAA 105777) and $P$. tephropora (TAA 103401, 103567, both collected in India) are identical (Fig. 3) except some very slight differences in the spectrum of A. pubertatis.

Are the small differences in the colour of basidiomata and skeletal hyphae sufficient to discriminate the three closely related genera? Ryvarden (1998) found that this was not the case, and rejoined Loweporus tephroporus with Perenniporia. When describing the genus Abundisporus for the other species of Loweporus, he stressed out the small, pale yellow slightly thickwalled non-dextrinoid basidiospores while Perenniporia species are characterized by thickwalled, truncate, hyaline and dextrinoid spores. However, some spores of Abundisporus species have thick walls, being slightly dextrinoid and almost truncate. On the other side, several Perenniporia species have weakly truncate or variably dextrinoid spores; in some species they have been described as hyaline to pale yellow or yellow (P. contraria (Berk. \& M.A. Curtis) Ryvarden, P. medulla-panis (Fr. : Fr.) Donk, P. mundula (Wakef.) Ryvarden, P. ochroleuca (Berk.) Ryvarden, P. subacida (Peck) Donk; see Ryvarden \& Johansen 1980). Spores of P. (Loweporus) tephropora have been described as hyaline by most authors but hyaline to yellow by Ryvarden and Johansen (1980).

In some poroid genera of Hymenochaetales, species with hyaline (white) and coloured (brown) spores may be observed within a single genus, such as Phellinus Quél. and Inonotus P. Karst. In Polyporaceae, there are only a few genera with coloured spores (Bondarcevomyces Parmasto, Phaeotrametes Wright, Pseudopiptoporus Ryvarden and Abundisporus), and this character has been considered to be useful to distinguish genera. If "Perenniporia" tephropo$r a$ has coloured spores, it would be reasonable to distinguish Abundisporus and Loweporus as subgenera of the genus Loweporus. But even then, the distinction between this genus and Perenniporia will remain vague until the spore colour of all Perenniporia species will be distinctly known. The reality of generic taxa unlike species is only in their common genealogy, and the scope of genera depends on the general genus "concept" in use in any time in any group of organisms. The contemporary polypore taxonomy is based on relatively small-scope genus "concept" which actually does not recognize subdivision of genera into infrageneric subdivisions, and favours splitting on generic level.

Acknowledgements: The authors of this paper acknowledge with gratitude late Dr. Endel Küllik for the study of infrared spectra, and Dr. Ilmi Parmasto for the study of VIS-absorption spectra of the basidiomata; Prof. Leif Ryvarden for giving his valuable collections to our hands, and for critically revising the manuscript. This work has been financially supported by the Estonian Science Foundation (Grant no. 4086). 


\section{References}

Boidin, J. 1958: Essai biotaxonomique sur les hydnés résupinés et les corticiés. - Rev. Mycol. Mem. horssér. 6 .

Boidin, J. \& Lanquetin, P. 1983: Basidiomycètes Aphyllophoralés epitheloïdes étalés. - Mycotaxon 16: 461-499.

Boidin, J. \& Lanquetin, P. 1984: Répertoire des données utiles pour effectuer les tests d'intercompatibilité chez les Basidiomycetes. I. Introduction. - Cryptog., Mycol. 5: 33-45.

Carranza-Morse, J. \& Gilbertson, R.L. 1986: Taxonomy of the Fomitopsis rosea complex (Aphyllophorales, Polyporaceae). - Mycotaxon 25: 469-486.

Corner, E.J.H. 1989: Ad Polyporaceas 5. - Beih. Nova Hedwigia 96: 1-218.

Gilbertson, R.L. \& Ryvarden, L. 1986: North American polypores. 1. - Fungiflora, Oslo. 436 pp.

Holmgren, P.K., N.H. Holmgren \& L.C. Barnett. 1990. Index herbariorum. Part I. The herbaria of the world, ed. 8. - Regnum Vegetabile 120.693 pp.
Ito, S. 1955: Mycological flora of Japan. Vol. II. Basidiomycetes. No. 4. - Yokendo, Tokyo. 450 pp. (In Japanese.)

Kornerup, A. \& Wanscher, J.H. 1967: Methuen handbook of colour. 2nd ed. - Methuen \& Co., London. $243 \mathrm{pp}$.

Marr, C.D. 1979: Laccase and tyrosinase oxidation of spot test reagents. - Mycotaxon 9:244-276.

Nobles, M.K. 1965: Identification of cultures of woodinhabiting Hymenomycetes. - Can. J. Bot. 43:10971139.

Parmasto, E. \& Parmasto, I. 1979: The xanthochroic reaction in Aphyllophorales. - Mycotaxon 8:201232.

Parmasto, E. \& Parmasto, I. 1987: Variation in basidiospores in the Hymenomycetes and its significance to their taxonomy. - Bibliotheca Mycologica 115: 1-168. J. Cramer, Berlin \& Stuttgart.

Ryvarden, L. 1998: African polypores - a review. Belg. Journ. Bot. 131: 150-155.

Ryvarden, L. \& Johansen, I. 1980: A preliminary polypore flora of East Africa. - Fungiflora, Oslo. $636 \mathrm{pp}$. 